\title{
LANGUAGE AND COGNITION
} An interdisciplinary journal of language and cognitive science

General Editors Daniel Casasanto Seana Coulson Vyvyan Evans Christopher Hart David Kemmerer Laura Michaelis Chris Sinha

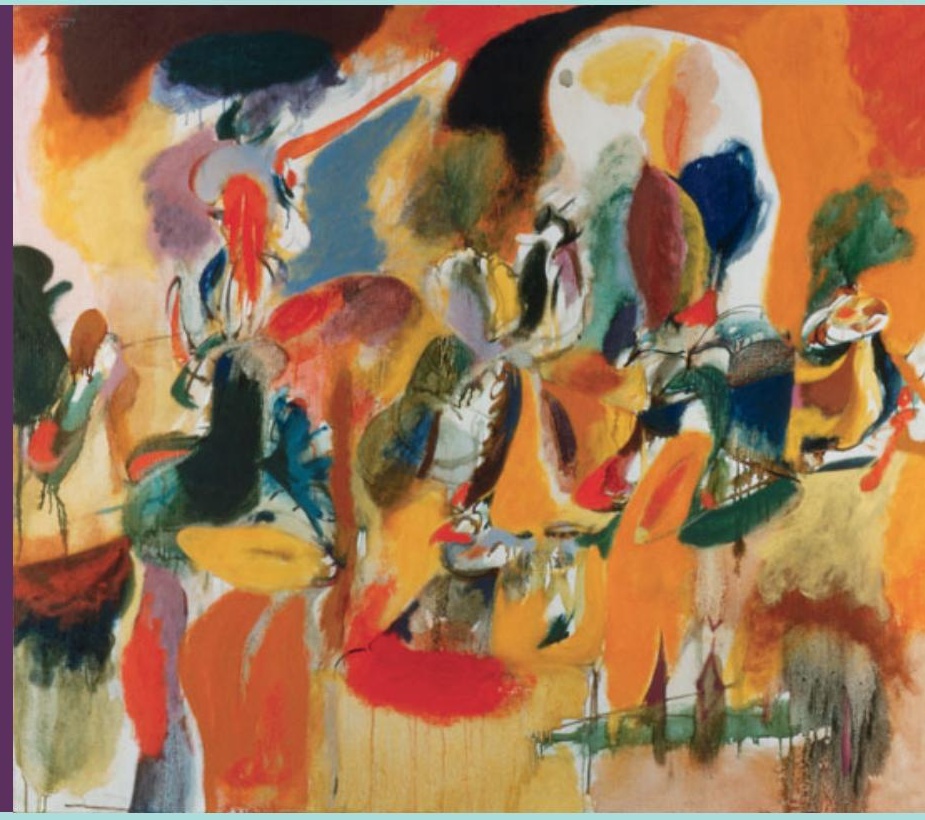

uk 


\title{
LANGUAGE AND COGNITION
}

\section{The Journal of the UK Cognitive Linguistics Association}

Language and Cognition is a venue for the publication of high quality peer-reviewed research of a theoretical and/or empirical/experimental nature, focusing on the interface between language and cognition. It is open to research from the full range of subject disciplines, theoretical backgrounds, and analytical frameworks that populate the language and cognitive sciences, on a wide range of topics. Research published in the journal adopts an interdisciplinary, comparative, multi-methodological approach to the study of language and cognition and their intersection.

\section{GENERAL EDITORS}

\author{
Dr Daniel Casasanto \\ University of Chicago, USA \\ Professor Seana Coulson \\ University of California, San Diego, USA \\ Professor Vyvyan Evans \\ Bangor University, UK \\ Dr Christopher Hart \\ Lancaster University, UK

\section{REVIEW EDITOR} \\ Professor Dylan Glynn \\ University of Paris VIII \\ Département d' Études des Pays Anglophones \\ 2 rue de la Liberté Saint-Denis \\ cedex 93526, France \\ Benjamin K. Bergen \\ University of California, San Diego, USA \\ Jules Davidoff \\ Goldsmiths' College, University of London, UK \\ Stanislas Dehaene \\ Collège de France, France \\ Alessandro Duranti \\ University of California, Los Angeles, USA \\ Nick Ellis \\ University of Michigan, USA \\ Nick Enfield \\ MPI for Psycholinguistics, Nijmegen, \\ The Netherlands \\ Gilles Fauconnier \\ University California, San Diego, USA \\ Michael Fortescue \\ University of Copenhagen, Denmark \\ Virginia Gathercole \\ Bangor University, UK \\ Dirk Geeraerts \\ University of Leuven, Belgium \\ Stefan Th. Gries \\ University of California, Santa Barbara, USA
}

Professor David Kemmerer

Purdue University, USA

Dr Laura Michaelis

University of Colorado, Boulder, USA

Professor Chris Sinha

Hunan University, China

\section{JOURNAL MANAGER}

Olivia Knapton

University of Birmingham, UK

\section{CONSULTANT EDITORS}

Peter Harder

University of Copenhagen, Denmark

Bernd Heine

University of Cologne, Germany

James Hurford

University of Edinburgh, UK

Dan Hutto

University of Hertfordshire, UK

Sotaro Kita

University of Warwick, UK

Jean-Pierre Koenig

State University of New York, Buffalo, USA

George Lakoff

University of California, Berkeley, USA

Aliyah Morgenstern

Université Sorbonne Nouvelle-Paris 3, France

Brigitte Nerlich

University of Nottingham, UK

Luc Steels

Free University, Brussels, Belgium 